\title{
Posttransplant Lymphoproliferative Disorders
}

\author{
Hazem A. H. Ibrahim ${ }^{1,2}$ and Kikkeri N. Naresh ${ }^{1}$ \\ ${ }^{1}$ Department of Histopathology, Hammersmith Hospital Campus, Imperial College Healthcare NHS Trust and Imperial College, \\ London W12 OHS, UK \\ ${ }^{2}$ Department of Histopathology, Faculty of Medicine, Mansoura University, Mansoura, Egypt
}

Correspondence should be addressed to Kikkeri N. Naresh, k.naresh@imperial.ac.uk

Received 29 November 2011; Accepted 24 January 2012

Academic Editor: Lorenzo Leoncini

Copyright $\odot 2012$ H. A. H. Ibrahim and K. N. Naresh. This is an open access article distributed under the Creative Commons Attribution License, which permits unrestricted use, distribution, and reproduction in any medium, provided the original work is properly cited.

\begin{abstract}
Posttransplant lymphoproliferative disorders (PTLDs) are a group of diseases that range from benign polyclonal to malignant monoclonal lymphoid proliferations. They arise secondary to treatment with immunosuppressive drugs given to prevent transplant rejection. Three main pathologic subsets/stages of evolution are recognised: early, polymorphic, and monomorphic lesions. The pathogenesis of PTLDs seems to be multifactorial. Among possible infective aetiologies, the role of EBV has been studied in depth, and the virus is thought to play a central role in driving the proliferation of EBV-infected B cells that leads to subsequent development of the lymphoproliferative disorder. It is apparent, however, that EBV is not solely responsible for the "neoplastic" state. Accumulated genetic alterations of oncogenes and tumour suppressor genes (deletions, mutations, rearrangements, and amplifications) and epigenetic changes (aberrant hypermethylation) that involve tumour suppressor genes are integral to the pathogenesis. Antigenic stimulation also plays an evident role in the pathogenesis of PTLDs. Plasmacytoid dendritic cells (PDCs) that are critical to fight viral infections have been thought to play a pathogenetically relevant role in PTLDs. Furthermore, regulatory T cells (Treg cells), which are modulators of immune reactions once incited, seem to have an important role in PTLDs where antigenic stimulation is key for the pathogenesis.
\end{abstract}

\section{Introduction}

Post-transplant lymphoproliferative disorders (PTLDs) are a group of diseases that range from benign polyclonal to malignant monoclonal lymphoid proliferations. They develop as a consequence of immunosuppression. PTLDs are characterised by the following: they are usually derived from B cells with preferential presentation as non-Hodgkin's lymphoma (as against Hodgkin's lymphoma), usually originate in extranodal sites, rarely affect skin, behave aggressively, and frequently harbour the Epstein-Barr virus (EBV) genome. Whilst most are high-grade B-cell non-Hodgkin's lymphoma (NHLs), a few are classical Hodgkin's lymphomas. Rare cases have also been shown to be either of T-cell or NK-cell lineages $[1,2]$.

T-cell neoplasms constitute $10 \%$ to $15 \%$ of all PTLDs, and about $75 \%$ of T-cell PTLDs, have been shown to be negative for EBV and to behave more aggressively. T-PTLDs usually develop later than B-PTLDs and patients are less likely to respond to reduction in immunosuppression $[3,4]$.

The abnormal B cells in solid organ transplant recipients originate usually from those of the recipient, while in recipients of bone marrow transplant they are of donor origin $[5,6]$.

\section{Onset, Frequency of Occurrence, and Risk Factors of PTLD}

PTLDs are classified as either early onset lesions which develop within one year, or late onset lesions, which develop more than one year after transplantation $[7,8]$.

The occurrence of PTLD varies between different studies, but the overall frequency is less than $2 \%$ in transplant recipients [9]. It differs according to many factors such as the age of the patient, the organ transplanted, type and dosage 
regimen of immunosuppressive drugs, and the pretransplant EBV serostatus [10].

(1) The age of the patient. children are more prone to developing PTLDs as they are usually naïve for Epstein-Barr virus (EBV) infection [10].

(2) The organ transplanted. the frequency of PTLD differs according to the type of organ transplanted. (Table 1) summarizes the frequency of PTLDs in transplant recipients $[6,9]$.

(3) Type and dosage regimen of immunosuppressive drugs. It has been reported that the risk of developing PTLD increases with the use of certain drugs such as tacrolimus and OKT3, especially when they are combined [11]. Despite the fact that immunosuppressive drugs are an established risk factor, it is still not well-understood whether the risk is due to the cumulative dose or peak levels of immunosuppressive drugs. The cumulative dose, however, is more likely to be the incriminating factor [12].

(4) The pretransplant EBV sero-status. EBV-naive recipients, being incapable of initiating an EBV-specific cytotoxic Tlymphocyte (CTC) response, are more liable to develop PTLD $[12,13]$. Nonexposure to EBV before transplantation remains the most important predisposing factor [13].

\section{Clinical Presentation}

The clinical manifestations vary from nonspecific symptoms in the form of fever, sweats, malaise, weight loss, and features of primary EBV infection in some patients, to sudden enlargement of tonsils, lymph nodes, or other extranodal lymphoid organs. Other organs such as the central nervous system, bone marrow, spleen, lung, small intestine, liver, and kidney may also be affected [10].

\section{Pathological Features and Classification of PTLDs}

Clinicopathologic features of major types of posttransplant lymphoproliferative disorders are summarised in Table 2. The classification of PTLDs is currently based on the WHO classification of lymphoid neoplasms (Table 3). Three main pathologic subsets/stages of evolution are recognised: early, polymorphic, and monomorphic lesions [3].

4.1. Early Lesions. Early lesions form one end of the spectrum of PTLD and mostly develop within one year after transplantation. These include two morphological types: plasma cell hyperplasia and infectious mononucleosis-like lesions. Early lesions more frequently involve tonsils, adenoids or lymph nodes than true extranodal sites. They do not invade or disturb the architecture of the affected tissue [3].

Plasmacytic hyperplasia shows numerous polytypic plasma cells and occasional immunoblasts. Infectious mono-
TABLE 1: Frequency of PTLD in different types of transplants.

\begin{tabular}{lc}
\hline $\begin{array}{l}\text { Organ } \\
\text { transplanted }\end{array}$ & $\begin{array}{c}\text { Reported risk of developing } \\
\text { PTLD \% and references }\end{array}$ \\
\hline Kidney & $1 \%$ \\
Liver & $2-5 \%$ \\
Heart & $2-5 \%$ \\
Lung & $1.8-7.9 \%$ \\
Heart-lung & $9.4 \%$ \\
Small bowel & up to $30 \%$ \\
Pancreas & $2.1 \%$ \\
Bone marrow & $<1 \%$ \\
\hline
\end{tabular}

nucleosis-like lesions show marked paracortical expansion by a cellular infiltrate composed of numerous immunoblasts and a mixed population of $\mathrm{T}$ cells and plasma cells. These lesions often show spontaneous regression or regress following reduction in immunosuppression [3]. Immunoblasts in infectious mononucleosis-like lesions frequently harbour EBV and express EBV-encoded RNA (EBER) or EBV-LMP-1. Early lesions rarely harbour clonal cytogenetic changes [14].

4.2. Polymorphic PTLDs. Polymorphic PTLDs affect nodal and extranodal tissues and show loss of tissue architecture and necrosis. Polymorphic PTLDs are composed of a mixed population of immunoblasts, plasma cells, intermediatesized lymphoid cells (incorporating a full range of Bcell morphology and differentiation), as well as occasional Hodgkin Reed Sternberg-like cells [15] (Figure 1). The Bcells are usually monotypic but may be polytypic. Nonetheless, a clonal pattern of $\mathrm{IgH}$ or episomal EBV genome is observed $[16,17]$. The majority of the lesions exhibit EBV latency type II or III (expressing EBER and EBV-LMP-1 with variable expression of EBV-EBNA2 and other viral antigens). A variable proportion of cases show regression in response to reduction in immune suppression while other cases may progress and require chemotherapy [3].

4.3. Monomorphic PTLDs. Monomorphic PTLDs (mPTLDs) can be either of $\mathrm{B}$ cell or T-cell lineage and resemble the typical types of non-Hodgkin lymphomas (NHLs) seen in immunocompetent patients, and they are usually monoclonal. They disturb the tissue architecture and spread to other organs. They are classified according to the WHO classification of lymphomas in immunocompetent patients. Monomorphic B-PTLDs show features of different morphologic variants of diffuse large B-cell lymphoma (DLBCL) in immunocompetent patients (iDLBCL) (immunoblastic, centroblastic, or anaplastic), Burkitt's lymphoma (BL), or plasmablastic lymphoma (PL). Almost all cases display a clonal pattern of IGH rearrangement, and EBV-positive cases show episomal EBV genome. mPTLDs can be EBV-negative, tend to be more aggressive, and only rarely respond to a reduction in immune suppression $[3,18]$. In addition, genetic alterations of $3 \mathrm{q} 27,8 \mathrm{q} 24.1$, and $14 \mathrm{q} 32$ have been described in monomorphic B-PTLDs [19]. The identification of similar cytogenetic alterations and clonal relationship 


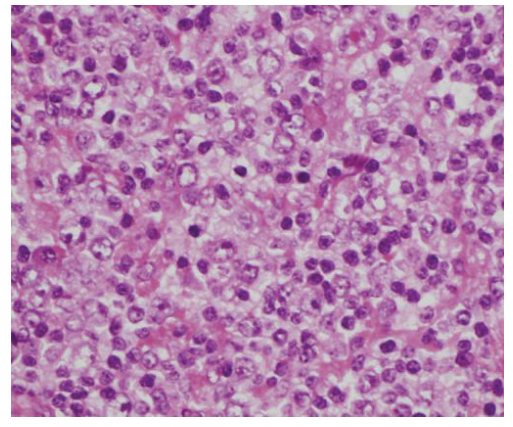

(a)

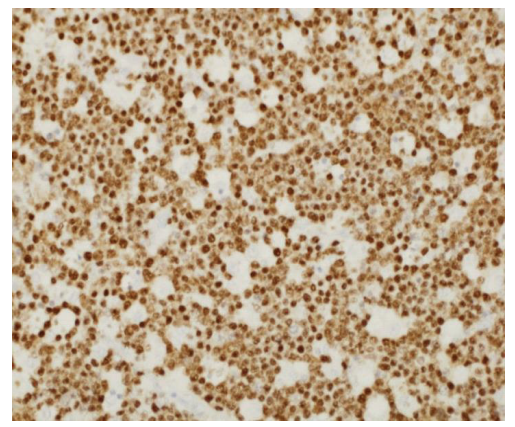

(d)

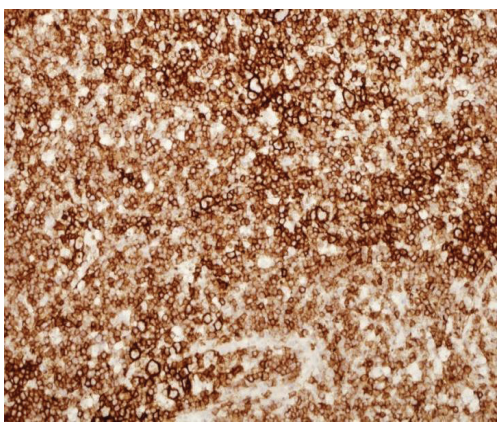

(b)

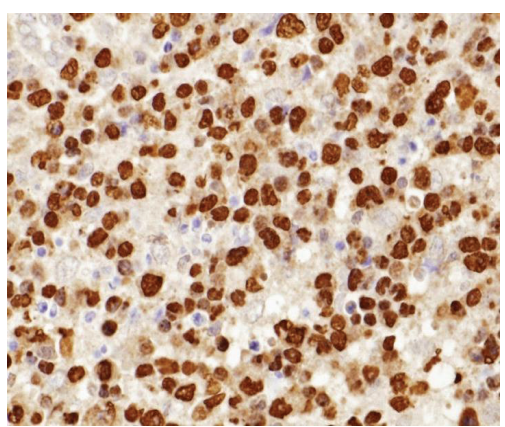

(e)

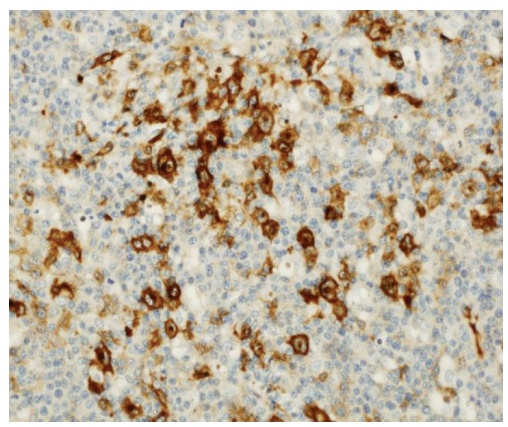

(c)

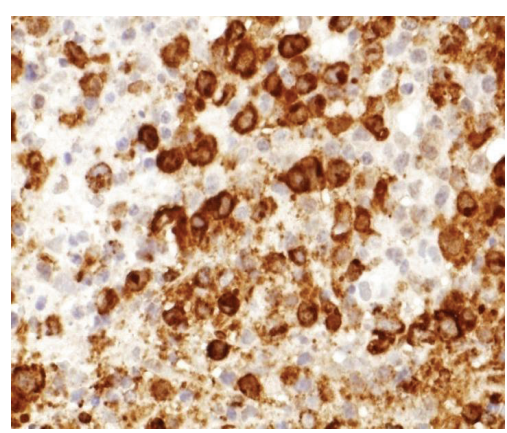

(f)

FIGURE 1: A typical case of polymorphic PTLD. (a) Infiltrate is a mix of plasma cells, small lymphoid cells and larger cells with nucleoli. The cells are positive for CD20 (b), CD30 (c), MUM1 (d), EBER (e), and EBV-LMP-1. Magnification: (b,d): $\times 100 ;(a, e, f): \times 200$.

TABLE 2: Clinicopathologic features of major types of posttransplant lymphoproliferative disorders.

\begin{tabular}{|c|c|c|c|}
\hline & $\begin{array}{l}\text { Early lesions (plasmacytic hyperplasia } \\
\text { and infectious mononucleosis-like) }\end{array}$ & Polymorphic PTLD & Monomorphic PTLD \\
\hline \multicolumn{4}{|l|}{ (i) Clinical features } \\
\hline (a) Age & Children and young adults & All age groups & All age groups \\
\hline (b) Organ involved & Tonsils or lymph nodes & $\begin{array}{l}\text { Lymph nodes, GIT, lung or } \\
\text { allograft }\end{array}$ & $\begin{array}{l}\text { Lymph node, any } \\
\text { extranodal site, including } \\
\text { bone marrow }\end{array}$ \\
\hline (c) Regression & $\begin{array}{l}\text { Usually regress either with minimal } \\
\text { reduction of immunosuppressive } \\
\text { drugs or spontaneously }\end{array}$ & $\begin{array}{l}\text { Some cases regress, others } \\
\text { progress }\end{array}$ & $\begin{array}{l}\text { Very rare. Most cases } \\
\text { progress rapidly }\end{array}$ \\
\hline \multicolumn{4}{|l|}{ (ii) Histopathological features } \\
\hline (a) Tissue architecture & No or partial effacement & Nearly complete effacement & Complete effacement \\
\hline (b) Nature of infiltrate & $\begin{array}{l}\text { Comprised mainly of plasma cells and } \\
\text { lymphoplasmacytoid cells in } \\
\text { plasmacytic hyperplasia, and } \\
\text { immunoblasts and plasmablasts in } \\
\text { infectious mononucleosis-like lesion }\end{array}$ & $\begin{array}{l}\text { Composed of a mixture of } \\
\text { plasma cells, small } \\
\text { lymphocytes, and large } \\
\text { activated cells }\end{array}$ & $\begin{array}{l}\text { Monotonous, similar to } \\
\text { that of usual type B-cell } \\
\text { NHL }\end{array}$ \\
\hline (c) Atypia & Absent & Present/absent in large cells & Present \\
\hline (d) Necrosis & Absent & Variable & Present (geographic) \\
\hline \multicolumn{4}{|l|}{ (iii) Molecular features } \\
\hline (a) $I g$ gene & Polyclonal in most cases & $\begin{array}{l}\text { Usually monoclonal; may } \\
\text { be oligo or polyclonal }\end{array}$ & Monoclonal \\
\hline (b) EBV & Usually nonclonal & Clonal & Clonal \\
\hline $\begin{array}{l}\text { (c) Structural alterations of } \\
\text { oncogenes and TSG }\end{array}$ & Usually absent & Usually absent & Usually present \\
\hline
\end{tabular}

Ig: immunoglobulin, EBV: Epstein-Barr virus, PTLD: posttransplant lymphoproliferative disorder, NHL: non-Hodgkin's lymphoma, TSG: tumour suppressor gene. 
TABLE 3: Categories of posttransplant lymphoproliferative disorders.

\section{(1) Early lesions}

(a) Reactive plasmacytic hyperplasia

(b) Infectious mononucleosis-like lesions

(2) Polymorphic PTLD

(3) Monomorphic PTLD

(classified according to lymphoma they resemble)

B-cell neoplasms

(a) Diffuse large B-cell lymphoma (DLBCL)

(b) Burkitt's lymphoma

(c) Plasma cell myeloma

(d) Plasmacytoma-like lesions

(e) Others*

T-cell neoplasms

(a) Peripheral T-cell lymphoma not otherwise specified

(b) Hepatosplenic T-cell lymphoma

(c) Others

(4) Classical Hodgkin's lymphoma-type (HL-PTLD) and HL-like PTLD**

* Indolent small B-cell lymphomas developing in transplant recipient are not included among the PTLD.

**HL-like PTLDs are better categorized either as a polymorphic or monomorphic PTLD based on the overall morphology.

between polymorphic PTLDs and MPTLD supports the hypothesis that PTLDs progress along a continuum from polyclonal early lesions to monoclonal $\operatorname{mPTLD}[3,20]$.

Plasmablastic lymphomas (PBL), which were originally described in HIV-infected people affecting the oral cavity, may occur as a PTLD. Nearly $60-75 \%$ of cases of PBL are EBV associated [21-23].

There are only a few cases of PTLDs reported in the literature that demonstrate both B- and T-cell clones. In a recently published study, however, monoclonal expansion of T-cell population which seems to arise from $\mathrm{CD}^{+} \mathrm{T}$ cells has been found to occur frequently in B-PTLDs, and these clonal T-cell populations coexist with monoclonal Bcell population in B-PTLDs. However, these clonal T-cell expansions do not constitute a clinical T-cell lymphoma [2426].

4.4. Hodgkin's Lymphoma-PTLD and HL-Like PTLD. The histological features of HL-type PTLD are similar to mixed cellularity or lymphocyte-depleted subtypes. The infiltrate is composed of scattered large pleomorphic mono- and binucleated Hodgkin/Reed-Sternberg giant cells in a background of small lymphocytes, B-immunoblasts intermingled with histiocytes, plasma cells, a few eosinophils, and neutrophils. The neoplastic cells are usually $\mathrm{CD} 30^{+}$, and $\mathrm{CD} 15^{+}, \mathrm{EBER}^{+}$, $\mathrm{CD}_{4}{ }^{-}$, OCT-2-/BOB1 [3]. In HL-like PTLD, the $\mathrm{EBV}^{+}$ cells are $\mathrm{CD}_{4} 5^{+}, \mathrm{CD} 20^{+}$, and $\mathrm{CD}^{+} 5^{+}$and $\mathrm{EBV}^{+}$small and medium-sized lymphoid cells may be present. Distinguishing HL-PTLD from HL-like lesions is sometimes difficult, and it has been suggested that the latter are better diagnosed as either a polymorphic or monomorphic PTLD based on the overall morphological features [3].

\section{Aetiology and Pathogenesis}

The pathogenesis of PTLD is multifactorial. EBV plays an important role in driving the proliferation of EBV-infected B cells. It is widely perceived, however, that it is not solely responsible for the "neoplastic" state, and that accumulation of different aberrations in protooncogenes and suppressor genes, and hypermethylation of suppressor genes are integral parts of the pathogenesis [27] (Figure 2).

\subsection{Viruses}

5.1.1. EBV. EBV is an oncogenic double-stranded DNA virus that infects and persists in memory B cells. Two phases of EBV infection have been recognized. The lytic phase is characterized by the expression of all EBV proteins and active viral replication, leading eventually to cell death and the release of virions. The latency phase involves infection of lymphoid B cells via their CD21 receptors, resulting in the formation of EBV episomes and the expression of a limited number of viral proteins [28].

This results in persistence of the virus in the lymphoid cells and their progeny without destruction of the infected cell. LMP-1 and LMP-2 viral proteins are believed to act as oncogenes, allowing $\mathrm{B}$ cells to escape cell death and proliferate autonomously [28]. There are three different latency patterns that correspond to the differentiation stages of B cells. These patterns are thought to play a major role in protecting EBV-infected cells from immunosurveillance [2931]. EBV-infected naive B cells expressing all latent antigens are said to have "type III latency." Infected naive B cells enter the germinal centre where they multiply and form clones. They express EBNA1, LMP-1, and LMP-2, and this is known as "type II latency" [32]. However, some only express EBNA-1 and 2 as well as small noncoding Epstein-Barr RNAs (EBERS) and are said to have "type I latency" as seen in Burkitt's lymphoma [33, 34].

Most PTLDs are associated with EBV, but nonetheless a proportion (42\% reported in one study) is EBV-negative, including $53 \%$ of the mPTLD cases $[35,36]$. There is a debate as to whether EBV-negative PTLDs are in fact incidental lymphomas developing in transplant patients, or true PTLDs that can regress following reduction of the immunosuppression [37]. It has to be noted that the lack of identifiable EBV, based on EBER or LMP-1 staining, does not necessarily imply that EBV-DNA is absent in all of these cases, or that EBV did not play a role in the pathogenesis of the EBVnegative lymphoid proliferations [38]. It has been suggested that EBV-negative PTLD may develop as a result of "hit and run" oncogenesis as does EBV-negative classical Hodgkin lymphoma (cHL) $[38,39]$. Chronic antigenic stimulation on the background of immune suppression is thought to play an essential role in the pathogenesis of EBV-negative PTLD [40]. 


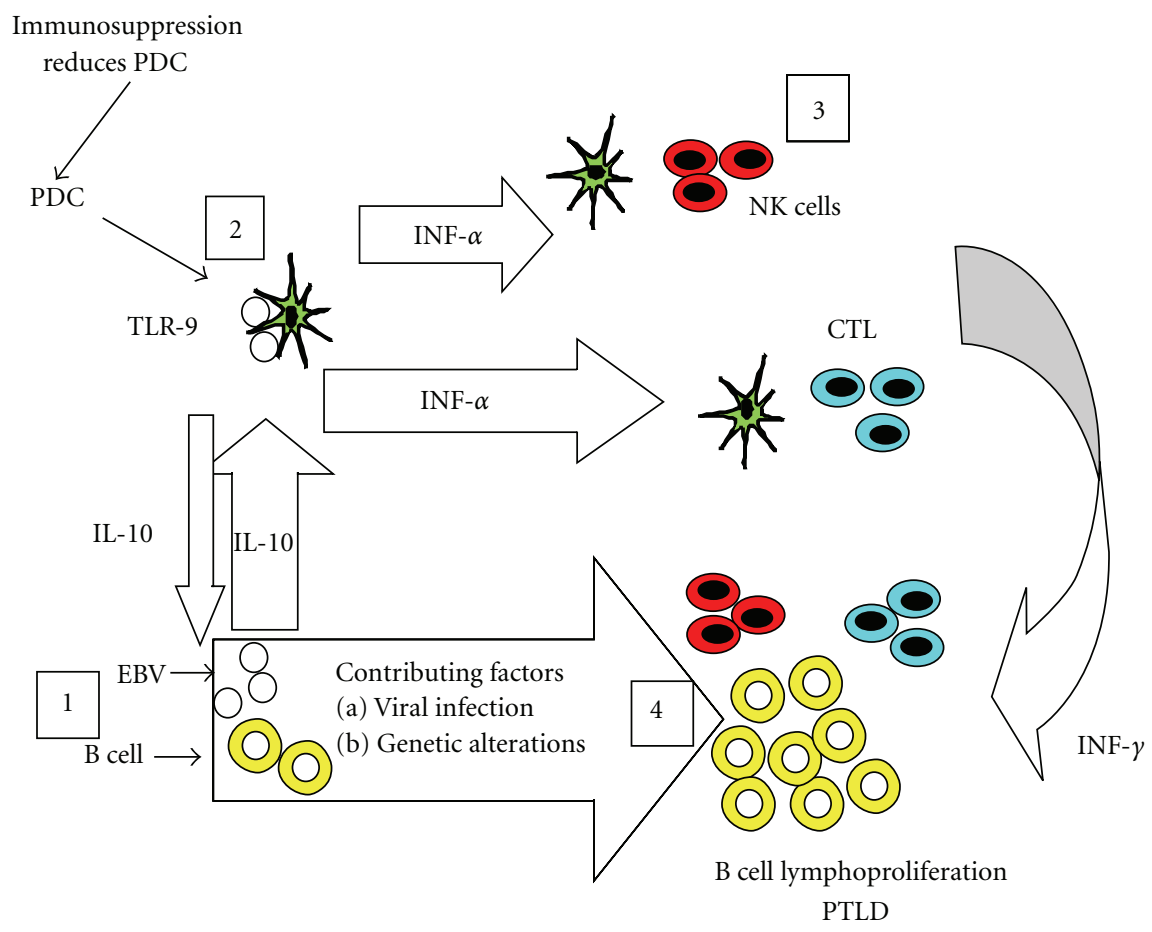

FIGURE 2: A proposed model of pathogenesis of EBV infection in the development of PTLDs in sold organ transplant recipients. CTL: cytotoxic T lymphocytes, IL-10: interleukin-10, INF- $\alpha$ : Interferon- $\alpha$, NK cells: natural killer cells, PDC: plasmacytoid dendritic cells, TLR-9: toll-like receptor-9.

B-PTLDs have been shown to be more frequently associated with type-A EBV genotype than type-B EBV $[41,42]$.

5.1.2. HHV-8. HHV-8 is a gamma-herpes virus that, like $\mathrm{EBV}$, infects $\mathrm{B}$ cells and acquires an episomal configuration in the nucleus and results in a state of latency. In the posttransplant setting, it has only been detected in cases of primary effusion lymphoma $[43,44]$. In a recently published study, KSHV/HHV-8 was found to be consistently absent in PTLD [45].

5.2. Molecular Alteration of Cellular Genes. Different genetic alterations among PTLDs are summarised in Table 4.

5.2.1. Microsatellite Instability. Lymphomas developing in immunocompetent patients are often characterized by relative genomic stability. In contrast, a small subset of PTLD is associated with microsatellite instability, which results from defects in DNA mismatch repair mechanisms [46]. These cases show mutations involving multiple genes, including $B A X$ and CASPASE5 (proapoptotic factors) and RAD50 (a DNA repair gene) [27].

5.2.2. Aberrant Somatic Hypermutation (ASHM). B cells in the germinal centre (GC) are subjected to a physiological phenomenon known as "somatic hypermutation" (SHM), which involves the introduction of single nucleotide substitution into their $\operatorname{IgV}$ genes [47]. It involves not only the $\mathrm{IgH}$ gene but also nonimmunoglobulin genes such as BCL6 and Fas/CD95. In more than 50\% of DLBCLs, SHMs can also affect some proto-oncogenes such as PAX5, PIM-1, RhoH/TTF, and $c$-MYC gene, which are involved in the pathogenesis of lymphoid neoplasms including some cases of PTLD [47].

\subsubsection{Other Genetic Alterations}

BCL6 Gene. The BCL6 gene is located on chromosome 3q27 and encodes a transcriptional repressor [48]. BCL6 rearrangement is very rarely seen in PTLDs, although it is the target of SHM in approximately $50 \%$ of PTLDs $[14,19]$.

c-MYC Gene. c-MYC gene is located on chromosome 8q24 and is the target of chromosomal breaks in most posttransplant Burkitt's lymphomas (PT-BL) $[14,49]$.

BCL2 Gene. BCL2 gene, an antiapoptotic gene, is located on chromosome $18 \mathrm{q} 21$. Although the BCL2 is amplified in a proportion of PTLDs, its rearrangement is a very rare event in PTLDs $[14,50]$.

TP53 Gene. The TP53 gene is a tumour suppressor gene located on $17 \mathrm{p} 13.1$ and is mutated or deleted in a small proportion of mPTLDs (DLBCL) [16].

IGH Gene. IGH gene is located on $14 \mathrm{q} 32$ and breakpoints involving the gene are detected in a small proportion of 
TABLE 4: Summary of different genetic alterations among PTLDs.

\begin{tabular}{|c|c|}
\hline Genetic alteration & Frequency \\
\hline \multicolumn{2}{|l|}{ BCL6 gene } \\
\hline (1) Rearrangement & Rare in PTLD \\
\hline (2) SHM & $50 \%$ of PTLD \\
\hline$c-M y c$ gene rearrangement & $100 \%$ PT-BL \\
\hline \multicolumn{2}{|l|}{ BCL2 gene } \\
\hline (1) Rearrangement & Very rare in PTLD \\
\hline (2) Amplification & A proportion of PTLD \\
\hline P53 gene mutation/deletion & Small proportion of $\mathrm{mPTLD}$ \\
\hline Translocations involving IG genes & $\begin{array}{l}\text { A small proportion of PTLD. Rarely in florid follicular hyperplasia in } \\
\text { posttransplant setting }\end{array}$ \\
\hline \multicolumn{2}{|l|}{ PAX5 gene } \\
\hline (1) Rearrangement & Very rare in PT-DLBCL \\
\hline (2) SHM & Very rare in PT-DLBCL \\
\hline (3) Amplification & A proportion of PTLD \\
\hline \multicolumn{2}{|l|}{ Chromosomal gains } \\
\hline \multicolumn{2}{|c|}{ (1) $3 \mathrm{q} 27,7 \mathrm{q}, 8 \mathrm{q} 24,12 \mathrm{q}, 12 \mathrm{p}, 18 \mathrm{q} 21,21 \mathrm{q}$} \\
\hline (2) $5 p$ and $11 p$ & PT-DLBCL = iDLBCL \\
\hline (3) $6 q 25.3$ & Recurrent in PT-BL \\
\hline (4) $1 \mathrm{q}, 11 \mathrm{q}$, and of chromosome 7 & PT-DLBCL \\
\hline \multicolumn{2}{|l|}{ Chromosomal loss } \\
\hline (1) $1 \mathrm{p}, 6 \mathrm{q}, 9 \mathrm{p}$, and $17 \mathrm{p} 13$ & Common to PTLD and lymphomas immune competent patients \\
\hline (2) $4 q, 17 q$, and $X p$ & In PTLD but not common in other lymphomas \\
\hline (3) $12 \mathrm{p}, 4 \mathrm{p}, 4 \mathrm{q}, 12 \mathrm{q}, 17 \mathrm{p}$, and $18 \mathrm{q}$ & Frequent in PT-DLBCL \\
\hline (4) $11 \mathrm{q} 25$ & Recurrent in PT-BL \\
\hline (5) 2 p16.1 (FRA2E) & $30 \%$ of PT-DLBCL (both in EBV positive and negative cases) \\
\hline (6) $17 \mathrm{p}$ & PT-DLBCL \\
\hline \multicolumn{2}{|l|}{ Aberrant hypermethylation of } \\
\hline (1) $M G M T$ & 75\% pPTLD and 93\% mPTLD. \\
\hline (2) DAP-kinase & $75 \% \mathrm{mPTLD}$ \\
\hline (3) TP73 & $20 \% \mathrm{mPTLD}$ \\
\hline (4) $S H P 1$ & $\sim 77 \%$ PT-DLBCLs, 75\% pPTLDs, 66\% PT-BLs \\
\hline (5) $C D K N 2 A$ & A small proportion of $\mathrm{mPTLD}$ \\
\hline
\end{tabular}

iDLBCL: immunocompetent diffuse large B cell lymphoma, mPTLD: monomorphic posttransplant lymphoproliferative disorders, pPTLD: polymorphic posttransplant lymphoproliferative disorders, PT-BL: posttransplant Burkitt lymphoma, PT-DLBCL: posttransplant diffuse large B cell lymphoma, SHM: Somatic hypermutation.

PTLD and rarely in florid follicular hyperplasia in posttransplant setting [14].

PAX5 Gene. PAX5 is the target of $\mathrm{t}(9 ; 14)(\mathrm{p} 13 ; \mathrm{q} 32)$ as well as ASHM in a very small proportion of mPTLD (DLBCL) $[51,52]$. A proportion of PTLDs has also been reported to have PAX5 gene amplification [53].

Other Chromosomal Changes. Comparative genomic hybridisation (CGH) analysis of PTLDs highlights some genetic changes similar to those occurring in the lymphoma of immunocompetent patients; for example, gains of $3 \mathrm{q} 27$, $7 \mathrm{q}, 8 \mathrm{q} 24,12 \mathrm{q}, 12 \mathrm{p}, 18 \mathrm{q} 21$, and $21 \mathrm{q}$ and losses of $1 \mathrm{p}, 6 \mathrm{q}$, $9 \mathrm{p}$, and $17 \mathrm{p} 13$. In addition, PTLDs show losses of $4 \mathrm{q}, 17 \mathrm{q}$ and $\mathrm{Xp}$ that are not common in other lymphomas [50, 53]. It has been demonstrated that posttransplant-DLBCLs (PT-DLBCLs), with a frequency similar to iDLBCLs, show gains of chromosomes 5p and 11p. Moreover, deletions of
$12 p, 4 p, 4 q, 12 q, 17 p$, and $18 q$ are frequently seen in PTDLBCLs [53]. The finding that iDLBCLs and a proportion of PTLDs (especially PT-DLBCLs) share some histogenetic and pathogenetic pathways is reinforced by the presence of recurrent chromosomal aberrations common to both PTLDs and iDLBCLs [54]. In addition, recurrent deletions on 11q25 and gains on 6q25.3 were observed in PT-BLs [53]. Rinaldi et al. [55] using high-density genome-wide SNP-based arrays, reported similar genomic complexity among PT-DLBCLs, HIV-DLBCLs, and iDLBCLs. Nonetheless, PT-DLBCLs displayed a genomic profile with distinctive features. It has been reported that the del(13q14.3) targets the locus coding for different noncoding RNAs [56]. The absence of del(13q14.3) in PT-DLBCLs is the most significant difference between PT-DLBCLs and iDLBCLs $[55,57]$. $\operatorname{Del}(13 q 14.3)$ is thought to be involved in immunosurveillance escape in the view that immunodeficiency-related lymphomas including PTLDs lack del(13q14.3) [55]. 
PT-DLBCLs have IgV mutational status and gene expression profiles similar to post-GC B cells $[3,20]$. Nonetheless, iDLBCLs of post-GC phenotype display genetic lesions that are different from PT-DLBCLs $[55,58,59]$. PT-DLBCLs have been reported to have gains of $1 \mathrm{q}, 11 \mathrm{q}$, and of chromosome 7 , in addition to losses at $17 \mathrm{p}$ (TP53) [55]. Compared with PT-DLBCLs, iDLBCLs were found to be more frequently associated with gains of 18q (BCL2 and NFATC1), and $\mathrm{LOH}$ at 6q21-q22 (approximately $7 \mathrm{Mb}$ telomeric from PRDM1(BLIMP1)) and at 6p21.32-p21.33 (HLA-DR locus) [55].

Craig et al. [60] used Affymetrix HU133A GeneChips to show that EBV-positive mPTLDs overexpress several interferon-induced genes as compared to EBV-negative mPTLDs. Furthermore, EBV-negative PTLDs overexpress genes corresponding to the B-cell receptor signalling pathways and a group of proliferation-related genes. These suggest that EBV-negative PTLDs are biologically distinct from EBV-positive PTLDs and are more similar to iDLBCL [60].

When compared with EBV-negative PT-DLBCLs, EBVpositive PT-DLBCLs have been described as having less recurrent lesions. However, del(2p16.1) is common in both EBV-negative and positive PT-DLBCLs [60].

"Fragile sites" are regions with marked genomic instability, present throughout the genome, that are often the sites of DNA breakage in malignant tumours and in cells exposed to specific chemical agents [61]. PT-DLBCLs have been described to have frequent interstitial deletions at $1 \mathrm{p} 32.2$, 2p16.1, 3p14.2, 4p14, 14q13.2, 20p12.3, and 20q13.32. Some of these deletions involve fragile sites such as FRA1B, FRA2E, and FRA3B. Del(2p16.1) (FRA2E) is the most common aberration in PT-DLBCLs, and the involvement is significantly higher than in iDLBCLs [55]. Some viruses including EBV and HHV-8 have been shown to incorporate themselves into the host genome, mainly at fragile sites, resulting in local genomic instability at the insertion sites [55]. Iatrogenically immunosuppressed posttransplant patients are more susceptible to a wide range of viruses which could integrate into the genome, particularly at these fragile sites [55]. The dissimilar pattern of breakage at fragile sites reported in PTDLBCLs and HIV-DLBCLs might be due to differences in the integration sites for various viruses [55].

5.2.4. Epigenetic Alteration (DNA Hypermethylation). Hypermethylation is an epigenetic phenomenon that alters the gene activity without changing its base sequences and is accomplished through DNA methyl transferase enzyme [62]. Aberrant hypermethylation (AH), which is a mechanism for tumour suppressor gene silencing alternative to deletion and/or mutation, has been implicated in the pathogenesis of lymphoproliferative disorders in the posttransplant setting [63].

Hypermethylation of Death-Associated Protein Kinase (DAP$k$ ). $D A P-k$ is a serine-threonine kinase, which plays an important role in apoptosis triggered by $\mathrm{TNF} \alpha, \operatorname{INF} \gamma$, and the FAS ligand. About $75 \%$ of mPTLDs display DAP- $k$ hypermethylation [64].
Hypermethylation of O6-Methylguanine-DNA Methyl-Transferase (MGMT). MGMT is one of the DNA repair genes that serves to protect against DNA damage. MGMT is methylated in nearly $75 \%$ and $93 \%$ polymorphic PTLDs, and mPTLDs respectively [65].

Hypermethylation of P73. P73 is a tumour suppressor gene that bears some functional and structural resemblance to TP53. It plays a role in cell cycle regulation and apoptosis and is hypermethylated in about 20\% mPTLDs [63].

Hypermethylation of P16. P16 is a tumour suppressor gene located on chromosome 9p21. It hinders the G1-S cell cycle transition by inhibiting the phosphorylation of Retinoblastoma protein. Martin et al. [66] described downregulation of P16/INK4a in subsets of mPTLDs (DLBCLs) that had an aggressive course but were not associated with EBV. There is a rare case report of an EBV-positive mPTLD (plasmablastic type) that showed $P 16$ hypermethylation [67].

Hypermethylation of SHP1 Gene. The SHP1 gene is located on chromosome 12p13 and encodes the SHP1 protein. The protein is expressed in hematopoietic cells and potentiates its negative effect on cell cycle regulation by inhibiting the JAKs/STATs pathway. In B-lymphocytes, therefore, it inhibits proliferation, and its deficiency through $\mathrm{AH}$ results in overgrowth [68]. Cerri et al. [69] reported SHP1 methylation in $76.5 \%$ of the PT-DLBCLs, $75 \%$ of the polymorphic PTLDs, $66 \%$ of the PT-BLs, and in a case of PT-myeloma.

5.3. Antigen Stimulation. Antigenic stimulation plays an important role in the pathogenesis of immunodeficiencyassociated lymphomas. Under normal circumstances B cells express the B-cell receptor (BCR), and the loss of a functional receptor through the acquisition of mutations results in apoptosis [47]. It has been demonstrated that EBV, through expression of LMP2A which simulates a BCR, protects BCR-lacking GC B cells from death, leading to lymphoma development [47]. There are a few reports of the existence of EBV-negative PTLDs that lack expression of sIg, pointing to the possibility of as yet unidentified genetic mechanisms that may rescue EBV-negative, BCR-lacking lymphocytes [20]. Molecular signs of antigen stimulation are evident in a fraction of PTLDs that exhibit a functional BCR [47].

\subsection{Role of Microenvironment}

5.4.1. Role of Plasmacytoid Dendritic Cells (PDCs). PDCs are potent antigen-presenting cells that originate from the hematopoietic stem cells in the bone marrow under the effect of some cytokines, principally Flt3L [70]. In the posttransplant scenario, EBV-stimulated PDCs produce insufficient concentrations of IFN- $\alpha$. Furthermore, the numbers of circulating blood PDC precursors are reduced in renal and cardiac transplant recipients. These are thought to play a significant role in the development of lymphoproliferative disorders $[71,72]$. In addition, EBV-stimulated PDCs produce the immunosuppressive cytokine IL-10, thereby allowing the 
virus-infected B cells to escape immunorecognition [73]. IL10 inhibits expression of costimulatory molecules, which in turn results in inability of monocytes and macrophages to activate $\mathrm{T}$ cells [74]. In addition, IL-10 suppresses the production of IFN- $\alpha$ and IFN- $\gamma$ by PDCs, T cells, and NK cells. It also has an inhibitory effect on antigen-specific activation and proliferation [75]. PDCs numbers are increased in some malignant neoplasms including cutaneous T-cell lymphoma [76]. PDCs are markedly decreased in number and are qualitatively altered in non-Hodgkin lymphoma, compared with reactive lymph nodes [76]. However, in some cases of classical Hodgkin lymphoma (cHL), there are increased numbers of PDCs present which may be attributed to the cytokines released in the microenvironment of cHL [76]. The observation of PDC clusters in tumour samples suggests that PDCs may also play an important role in the pathogenesis of cutaneous marginal zone B-cell lymphoma [77]. Based on the finding of significantly higher numbers of PDCs in the tumour microenvironment of early lesions of B-PTLDs compared to polymorphic and monomorphic lesion, and in PT-DLBCL compared to iDLBCL, PDCs have been suggested to play a pathogenetically relevant role in PTLDs [78].

5.4.2. Role of Treg Cells. Treg cells are $\mathrm{CD}^{+}$and $\mathrm{CD} 25^{+} \mathrm{T}$ lymphocytes that are a subset of immunoregulatory cells, and have the ability to suppress immune responses. There is a subpopulation of Treg cells which express CD8 and not CD4 [79]. When Treg cells undergo activation via their TCR, they inhibit the proliferation of $\mathrm{CD} 4^{+}$and $\mathrm{CD} 8^{+} \mathrm{T}$ lymphocytes, through the release of cytokines such as IL-10 and TGF- $\beta$ $[80,81]$. The intratumoural Treg cells have been shown to have an inhibitory effect on the production and release of perforin and granzyme $\mathrm{B}$, which is necessary for the effector functions of $\mathrm{CD}^{+}$cells and cytotoxic T-cell-mediated lysis of tumour cells [82]. Treg cells are also known to have a direct effect on B lymphocytes and inhibit the production of immunoglobulins [83]. Treg cells can suppress the growth of some tumours in addition to their role in suppressing the antitumour immune response [84]. Higher numbers of Treg cells have been described as predictors of both improved survival in follicular lymphoma and therapeutic response [85]. Treg cells are found in higher numbers in tissue samples of B-cell lymphomas as compared to reactive lymph nodes or tonsils. This is thought to be due to the attraction of Treg cells to the tumour microenvironment through CCL22 secreted by the lymphoma cells $[85,86]$. It has been previously shown that in recipients of solid organ transplants who are on multiple immunosuppressive drugs, the levels FOXP3 ${ }^{+}$ Treg cells reduce in the peripheral blood, possibly due to redistribution into tissues and lymphoid organs [87]. The numbers of Treg cells in the tumour microenvironment of PTLDs have been shown to have no impact on patient survival [88].

\section{Conclusion}

PTLDs are group of diseases that range from benign polyclonal to malignant monoclonal lymphoid proliferations. Genetic and epigenetic alterations as well as viruses, notably EBV, contribute towards the development of PTLDs. Common genetic rearrangements which are frequent in immune competent lymphoma are rare in PTLDs. Microenvironment-resident PDCs and Treg cells are likely to play a critical role in the pathogenesis of PTLDs. Therefore, further studies investigating the cytokines secreted by PDCs and Teg cells are required to substantiate and further clarify their precise role in the pathogenesis of PTLD.

\section{References}

[1] Y. L. Kwong, C. C. K. Lam, and T. M. Chan, "Post-transplantation lymphoproliferative disease of natural killer cell lineage: a clinicopathological and molecular analysis," British Journal of Haematology, vol. 110, no. 1, pp. 197-202, 2000.

[2] S. Kumar, D. Kumar, D. W. Kingma, and E. S. Jaffe, "EpsteinBarr virus-associated T-cell lymphoma in a renal transplant patient," American Journal of Surgical Pathology, vol. 17, no. 10, pp. 1046-1053, 1993.

[3] S. H. Swerdlow, S. A. Webber, A. Chadburn et al., "Posttransplant lymphoproliferative disorders," in WHO Classification of Tumours of Haematopoietic and Lymphoid Tissues, S. H. Swerdlow, E. Campo, N. L. Harris et al., Eds., pp. 343-349, IARC, Lyon, France, 2008.

[4] C. C. Yin, L. J. Medeiros, L. V. Abruzzo, D. Jones, A. I. Farhood, and V. A. Thomazy, "EBV-associated B- and Tcell posttransplant lymphoproliferative disorders following primary EBV infection in a kidney transplant recipient," American Journal of Clinical Pathology, vol. 123, no. 2, pp. 222228, 2005.

[5] A. Chadburn, N. Suciu-Foca, E. Cesarman, E. Reed, R. E. Michler, and D. R. Knowles, "Post-transplantation lymphoproliferative disorders arising in solid organ transplant recipients are usually of recipient origin," American Journal of Pathology, vol. 147, no. 6, pp. 1862-1870, 1995.

[6] M. M. Zutter, P. J. Martin, G. E. Sale et al., "Epstein-Barr virus lymphoproliferation after bone marrow transplantation," Blood, vol. 72, no. 2, pp. 520-529, 1988.

[7] I. M. Ghobrial, T. M. Habermann, W. R. Macon et al., "Differences between early and late posttransplant lymphoproliferative disorders in solid organ transplant patients: are they two different diseases?" Transplantation, vol. 79, no. 2, pp. 244-247, 2005.

[8] J. H. Choi, B. B. Park, C. Suh, J. H. Won, W. S. Lee, and H. J. Shin, "Clinical characteristics of monomorphic posttransplant lymphoproliferative disorders," Journal of Korean Medical Science, vol. 25, no. 4, pp. 523-526, 2010.

[9] V. R. Dharnidharka, A. H. Tejani, P. L. Ho, and W. E. Harmon, "Post-transplant lymphoproliferative disorder in the United States: young Caucasian males are at highest risk," American Journal of Transplantation, vol. 2, no. 10, pp. 993-998, 2002.

[10] Dharnidharka R. Vikas, 2006, http://www.emedicine.com/ ped/topic2851.htm.

[11] K. L. Cox, L. S. Lawrence-Miyasaki, R. Garcia-Kennedy et al., "An increased incidence of Epstein-Barr virus infection and lymphoproliferative disorder in young children on FK506 after 
liver transplantation," Transplantation, vol. 59, no. 4, pp. 524 529, 1995.

[12] U. D. Allen, G. Farkas, D. Hébert et al., "Risk factors for posttransplant lymphoproliferative disorder in pediatric patients: a case-control study," Pediatric Transplantation, vol. 9, no. 4, pp. 450-455, 2005.

[13] B. Z. Katz, E. Pahl, S. E. Crawford et al., "Case-control study of risk factors for the development of post-transplant lymphoproliferative disease in a pediatric heart transplant cohort," Pediatric Transplantation, vol. 11, no. 1, pp. 58-65, 2007.

[14] E. Vakiani, S. V. Nandula, S. Subramaniyam et al., "Cytogenetic analysis of B-cell posttransplant lymphoproliferations validates the World Health Organization classification and suggests inclusion of florid follicular hyperplasia as a precursor lesion," Human Pathology, vol. 38, no. 2, pp. 315-325, 2007.

[15] N. L. Harris, J. A. Ferry, and S. H. Swerdlow, "Posttransplant lymphoproliferative disorders: summary of Society for Hematopathology Workshop," Seminars in Diagnostic Pathology, vol. 14, pp. 8-14, 1997.

[16] D. M. Knowles, E. Cesarman, A. Chadburn et al., "Correlative morphologic and molecular genetic analysis demonstrates three distinct categories of posttransplantation lymphoproliferative disorders," Blood, vol. 85, no. 2, pp. 552-565, 1995.

[17] A. Chadburn, J. M. Chen, D. T. Hsu et al., "The morphologic and molecular genetic categories of posttransplantation lymphoproliferative disorders are clinically relevant," Cancer, vol. 82, no. 10, pp. 1978-1987, 1998.

[18] M. B. Y. Tang, E. S. T. Tan, and S. H. Tan, "Late-onset EpsteinBarr virus-negative post-transplant lymphoproliferative disorder presenting as ulcerated necrotic papules and nodules in a renal transplant patient," Australasian Journal of Dermatology, vol. 49, no. 2, pp. 100-102, 2008.

[19] M. Djokic, M. M. Le Beau, L. J. Swinnen et al., "Post-transplant lymphoproliferative disorder subtypes correlate with different recurring chromosomal abnormalities," Genes Chromosomes and Cancer, vol. 45, no. 3, pp. 313-318, 2006.

[20] E. Vakiani, K. Basso, U. Klein et al., "Genetic and phenotypic analysis of B-cell post-transplant lymphoproliferative disorders provides insights into disease biology," Hematological Oncology, vol. 26, no. 4, pp. 199-211, 2008.

[21] J. Borenstein, F. Pezzella, and K. C. Gatter, "Plasmablastic lymphomas may occur as post-transplant lymphoproliferative disorders," Histopathology, vol. 51, no. 6, pp. 774-777, 2007.

[22] K. N. Naresh, "Lymphoproliferative disorders in the immunosuppressed," Diagnostic Histopathology, vol. 16, no. 4, pp. 206$215,2010$.

[23] C. Hernandez, A. S. Cetner, and E. L. Wiley, "Cutaneous presentation of plasmablastic post-transplant lymphoproliferative disorder in a 14-month-old," Pediatric Dermatology, vol. 26, no. 6, pp. 713-716, 2009.

[24] A. Morovic, E. S. Jaffe, M. Raffeld et al., " Metachronous EBV-associated B-cell and T-cell posttransplant lymphoproliferative disorders in a heart transplant recipient," American Journal of Surgical Pathology, vol. 33, pp. 149-154, 2009.

[25] J. Esquiche León, A. Takahama Júnior, J. Vassallo, F. A. Soares, O. P. De Almeida, and M. Ajudarte Lopes, "EBVassociated polymorphic posttransplant lymphoproliferative disorder presenting as gingival ulcers," International Journal of Surgical Pathology, vol. 19, no. 2, pp. 241-246, 2011.

[26] H. A. H. Ibrahim, L. P. Menasce, S. Pomplun, M. Burke, M. Bower, and K. N. Naresh, "Presence of monoclonal Tcell populations in B-cell post-transplant lymphoproliferative disorders," Modern Pathology, vol. 24, pp. 232-240, 2011.
[27] D. Capello, D. Rossi, and G. Gaidano, "Post-transplant lymphoproliferative disorders: molecular basis of disease histogenesis and pathogenesis," Hematological Oncology, vol. 23, no. 2, pp. 61-67, 2005.

[28] R. Küppers, "B cells under influence: transformation of B cells by Epstein-Barr virus," Nature Reviews Immunology, vol. 3, no. 10, pp. 801-812, 2003.

[29] A. Rickinson, "Epstein-Barr virus," Virus Research, vol. 82, pp. 109-113, 2002.

[30] D. A. Thorley-Lawson, "Epstein-Barr virus: exploiting the immune system," Nature Reviews Immunology, vol. 1, no. 1, pp. 75-82, 2001.

[31] A. Chen, B. Zhao, E. Kieff, J. C. Aster, and F. Wang, "EBNA-3Band EBNA-3C-regulated cellular genes in Epstein-Barr virusimmortalized lymphoblastoid cell lines," Journal of Virology, vol. 80, no. 20, pp. 10139-10150, 2006.

[32] D. A. Thorley-Lawson, "Epstein-Barr virus: exploiting the immune system," Nature Reviews Immunology, vol. 1, no. 1, pp. 75-82, 2001.

[33] F. Sbih-Lammali, D. Djennaoui, H. Belaoui, A. Bouguermouh, G. Decaussin, and T. Ooka, "Transcriptional expression of Epstein-Barr virus genes and proto-oncogenes in North African nasopharyngeal carcinoma," Journal of Medical Virology, vol. 49, no. 1, pp. 7-14, 1996.

[34] D. Hochberg, J. M. Middeldorp, M. Catalina, J. L. Sullivan, K. Luzuriaga, and D. A. Thorley-Lawson, "Demonstration of the Burkitt's lymphoma Epstein-Barr virus phenotype in dividing latently infected memory cells in vivo," Proceedings of the National Academy of Sciences of the United States of America, vol. 101, no. 1, pp. 239-244, 2004.

[35] D. Capello, M. Cerri, G. Muti et al., "Molecular histogenesis of posttransplantation lymphoproliferative disorders," Blood, vol. 102, no. 10, pp. 3775-3785, 2003.

[36] B. P. Nelson, M. A. Nalesnik, D. W. Bahler, J. Locker, J. J. Fung, and S. H. Swerdlow, "Epstein-Barr virus-negative posttransplant lymphoproliferative disorders: a distinct entity?" American Journal of Surgical Pathology, vol. 24, no. 3, pp. 375$385,2000$.

[37] L. R. Johnson, M. A. Nalesnik, and S. H. Swerdlow, "Impact of Epstein-Barr virus in monomorphic B-cell posttransplant lymphoproliferative disorders: a histogenetic study," American Journal of Surgical Pathology, vol. 30, no. 12, pp. 1604-1612, 2006.

[38] Y. J. Gan, B. I. Razzouk, T. Su, and J. W. Sixbey, "A defective, rearranged Epstein-Barr virus genome in EBER-negative and EBER-positive Hodgkin's disease," American Journal of Pathology, vol. 160, no. 3, pp. 781-786, 2002.

[39] R. F. Ambinder, "Gammaherpesviruses and 'hit-and-run' oncogenesis," American Journal of Pathology, vol. 156, no. 1, pp. 1-3, 2000.

[40] S. A. Birkeland and S. Hamilton-Dutoit, "Is posttransplant lymphoproliferative disorder (PTLD) caused by any specific immunosuppressive drug or by the transplantation per se?" Transplantation, vol. 76, no. 6, pp. 984-988, 2003.

[41] D. Frank, E. Cesarman, Yi Fang Liu, R. E. Michler, and D. M. Knowles, "Posttransplantation lymphoproliferative disorders frequently contain type A and not type B Epstein-Barr virus," Blood, vol. 85, no. 5, pp. 1396-1403, 1995.

[42] H. A. H. Ibrahim, L. P. Menasce, S. Pomplun, M. Burke, M. Bower, and K. N. Naresh, "Epstein-Barr virus (EBV) genotypes among human immunodeficiency virus (HIV)related B-cell Lymphomas and B-cell post-transplant lymphoproliferative disorders (B-PTLD)-late-onset lymphomas, especially in the HIV setting, are associated with type-B-EBV," 
European Journal of Haematology, vol. 85, no. 3, pp. 227-230, 2010.

[43] J. Kapelushnik, S. Ariad, D. Benharroch et al., "Post renal transplantation human herpesvirus 8-associated lymphoproliferative disorder and Kaposi's sarcoma," British Journal of Haematology, vol. 113, no. 2, pp. 425-428, 2001.

[44] G. Gaidano and A. Carbone, "Primary effusion lymphoma: a liquid phase lymphoma of fluid-filled body cavities," Advances in Cancer Research, vol. 80, pp. 115-146, 2000.

[45] W. Chen, Q. Huang, C. W. Zuppan et al., "Complete absence of $\mathrm{KSHV} / \mathrm{HHV}-8$ in posttransplant lymphoproliferative disorders an immunohistochemical and molecular study of 52 cases," American Journal of Clinical Pathology, vol. 131, no. 5, pp. 632-639, 2009.

[46] A. Duval, M. Raphael, C. Brennetot et al., "The mutator pathway is a feature of immunodeficiency-related lymphomas," Proceedings of the National Academy of Sciences of the United States of America, vol. 101, no. 14, pp. 5002-5007, 2004.

[47] D. Capello and G. Gaidano, "Post-transplant lymphoproliferative disorders: role of viral infection, genetic lesions and antigen stimulation in the pathogenesis of the disease," Mediterranean Journal of Hematology and Infectious Diseases, vol. 1, article e2009018, no. 2, 2009.

[48] B. W. Baron, G. Nucifora, N. McCabe, R. Espinosa, M. M. Le Beau, and T. W. McKeithan, "Identification of the gene associated with the recurring chromosomal translocations $\mathrm{t}(3 ; 14)(\mathrm{q} 27 ; \mathrm{q} 32)$ and $\mathrm{t}(3 ; 22)$ (q27;q11) in B-cell lymphomas," Proceedings of the National Academy of Sciences of the United States of America, vol. 90, no. 11, pp. 5262-5266, 1993.

[49] K. Windebank, T. Walwyn, R. Kirk et al., "Post cardiac transplantation lymphoproliferative disorder presenting as $\mathrm{t}(8 ; 14)$ Burkitt leukaemia/lymphoma treated with low intensity chemotherapy and rituximab," Pediatric Blood and Cancer, vol. 53, no. 3, pp. 392-396, 2009.

[50] H. A. Poirel, A. Bernheim, A. Schneider et al., "Characteristic pattern of chromosomal imbalances in posttransplantation lymphoproliferative disorders: correlation with histopathological subcategories and EBV status," Transplantation, vol. 80, no. 2, pp. 176-184, 2005.

[51] M. Cerri, D. Capello, G. Muti et al., "Aberrant somatic hypermutation in post-transplant lymphoproliferative disorders," British Journal of Haematology, vol. 127, no. 3, pp. 362-364, 2004.

[52] O. Fasan, C. Willmott, B. Czepulkowski et al., "Epstein-Barr virus-related post-transplant lymphoproliferative disorder with $\mathrm{t}(9 ; 14)(\mathrm{p} 11 \sim 12 ; \mathrm{q} 32)$," Cancer Genetics and Cytogenetics, vol. 142, no. 2, pp. 134-136, 2003.

[53] A. Rinaldi, I. Kwee, G. Poretti et al., "Comparative genomewide profiling of post-transplant lymphoproliferative disorders and diffuse large B-cell lymphomas," British Journal of Haematology, vol. 134, no. 1, pp. 27-36, 2006.

[54] D. Capello, D. Rossi, and G. Gaidano, "Post-transplant lymphoproliferative disorders: molecular basis of disease histogenesis and pathogenesis," Hematological Oncology, vol. 23, no. 2, pp. 61-67, 2005.

[55] A. Rinaldi, D. Capello, M. Scandurra et al., "Single nucleotide polymorphism-arrays provide new insights in the pathogenesis of post-transplant diffuse large B-cell lymphoma," British Journal of Haematology, vol. 149, no. 4, pp. 569-577, 2010.

[56] B. I. Ferreira, J. F. García, J. Suela et al., "Comparative genome profiling across subtypes of low-grade B-cell lymphoma identifies type-specific and common aberrations that target genes with a role in B-cell neoplasia," Haematologica, vol. 93, no. 5, pp. 670-679, 2008.
[57] D. Capello, M. Scandurra, G. Poretti et al., "Genome wide DNA-profiling of HIV-related B-cell lymphomas," British Journal of Haematology, vol. 148, no. 2, pp. 245-255, 2010.

[58] G. Lenz, G. W. Wright, N. C. T. Emre et al., "Molecular subtypes of diffuse large B-cell lymphoma arise by distinct genetic pathways," Proceedings of the National Academy of Sciences of the United States of America, vol. 105, no. 36, pp. 13520-13525, 2008.

[59] M. Compagno, W. K. Lim, A. Grunn et al., "Mutations of multiple genes cause deregulation of NF-B in diffuse large Bcell lymphoma," Nature, vol. 459, no. 7247, pp. 717-721, 2009.

[60] F. E. Craig, L. R. Johnson, S. A. K. Harvey et al., "Gene expression profiling of epstein-barr virus-positive and-negative monomorphic B-cell posttransplant lymphoproliferative disorders," Diagnostic Molecular Pathology, vol. 16, no. 3, pp. 158$168,2007$.

[61] C. H. Freudenreich, "Chromosome fragility: molecular mechanisms and cellular consequences," Frontiers in Bioscience, vol. 12, pp. 4911-4924, 2007.

[62] P. M. Das and R. Singal, "DNA methylation and cancer," Journal of Clinical Oncology, vol. 22, no. 22, pp. 4632-4642, 2004.

[63] D. Rossi, G. Gaidano, A. Gloghini et al., "Frequent aberrant promoter hypermethylation of O6-methylguanine- DNA methyltransferase and death-associated protein kinase genes in immunodeficiency-related lymphomas," British Journal of Haematology, vol. 123, no. 3, pp. 475-478, 2003.

[64] S. Bialik and A. Kimchi, "DAP-kinase as a target for drug design in cancer and diseases associated with accelerated cell death," Seminars in Cancer Biology, vol. 14, no. 4, pp. 283-294, 2004.

[65] D. Capello, E. Berra, M. Cerri, and G. Gaidano, "Posttransplant lymphoproliferative disorders: molecular analysis of histogenesis and pathogenesis," Minerva Medica, vol. 95, no. 1, pp. 53-64, 2004.

[66] A. Martin, F. Baran-Marzak, S. El Mansouri et al., "Expression of p16/INK4a in posttransplantation lymphoproliferative disorders," American Journal of Pathology, vol. 156, no. 5, pp. 1573-1579, 2000.

[67] J. L. Arbiser, K. P. Mann, E. M. Losken et al., "Presence of p16 hypermethylation and Epstein-Barr virus infection in transplant-associated hematolymphoid neoplasm of the skin," Journal of the American Academy of Dermatology, vol. 55, no. 5, pp. 794-798, 2006.

[68] J. G. Cyster and C. C. Goodnow, "Protein tyrosine phosphatase $1 \mathrm{C}$ negatively regulates antigen receptor signaling in B lymphocytes and determines thresholds for negative selection," Immunity, vol. 2, no. 1, pp. 13-24, 1995.

[69] M. Cerri, C. Deambrogi, D. Rossi et al., "Aberrant methylation of SHP-1 (SH2-containing phosphatase 1) and SOCS-1 (suppressor of cytokine signaling 1) genes in immunodeficiencyrelated lymphomas," in Proceedings of the 12th Congress of the European Hematology Association, vol. 92, supplement 2, abstract 0289 of Haematologica, p. 105, June 2007.

[70] W. Barchet, M. Cella, and M. Colonna, "Plasmacytoid dendritic cells-virus experts of innate immunity," Seminars in Immunology, vol. 17, no. 4, pp. 253-261, 2005.

[71] W. H. Lim, S. Kireta, A. W. Thomson, G. R. Russ, and P. T. H. Coates, "Renal transplantation reverses functional deficiencies in circulating dendritic cell subsets in chronic renal failure patients," Transplantation, vol. 81, no. 2, pp. 160-168, 2006. 
[72] H. Hackstein, F. C. Renner, A. Bohnert et al., "Dendritic cell deficiency in the blood of kidney transplant patients on longterm immunosuppression: results of a prospective matchedcohort study," American Journal of Transplantation, vol. 5, no. 12, pp. 2945-2953, 2005.

[73] H. Gary-Gouy, P. Lebon, and A. H. Dalloul, “Type I interferon production by plasmacytoid dendritic cells and monocytes is triggered by viruses, but the level of production is controlled by distinct cytokines," Journal of Interferon and Cytokine Research, vol. 22, no. 6, pp. 653-659, 2002.

[74] S. Salek-Ardakani, J. R. Arrand, and M. Mackett, "EpsteinBarr virus encoded interleukin-10 inhibits HLA-class I, ICAM-1, and B7 expression on human monocytes: implications for immune evasion by EBV," Virology, vol. 304, no. 2, pp. 342-351, 2002.

[75] S. Mocellin, M. C. Panelli, E. Wang, D. Nagorsen, and F. M. Marincola, "The dual role of IL-10," Trends in Immunology, vol. 24, no. 1, pp. 36-43, 2003.

[76] A. G. Jegalian, F. Facchetti, and E. S. Jaffe, "Plasmacytoid dendritic cells physiologic roles and pathologic states," Advances in Anatomic Pathology, vol. 16, no. 6, pp. 392-404, 2009.

[77] H. Kutzner, H. Kerl, M. C. Pfaltz, and W. Kempf, "CD123positive plasmacytoid dendritic cells in primary cutaneous marginal zone b-cell lymphoma: diagnostic and pathogenetic implications," American Journal of Surgical Pathology, vol. 33, no. 9, pp. 1307-1313, 2009.

[78] H. A. H. Ibrahim, L. Menasce, S. Pomplun, M. Burke, M. Bower, and K. N. Naresh, "Tumour infiltrating plasmacytoid dendritic cells in B cell post-transplant lymphoproliferative disorders, human immunodeficiency virus-associated B cell lymphomas and immune competent diffuse large B cell lymphomas," Histopathology, vol. 59, no. 1, pp. 152-156, 2011.

[79] E. Xystrakis, A. S. Dejean, I. Bernard et al., "Identification of a novel natural regulatory CD8 T-cell subset and analysis of its mechanism of regulation," Blood, vol. 104, no. 10, pp. 32943301, 2004.

[80] A. M. Thornton and E. M. Shevach, "CD4 ${ }^{+} \mathrm{CD} 25^{+}$ immunoregulatory $\mathrm{T}$ cells suppress polyclonal $\mathrm{T}$ cell activation in vitro by inhibiting interleukin 2 production," Journal of Experimental Medicine, vol. 188, no. 2, pp. 287-296, 1998.

[81] C. A. Piccirillo and E. M. Shevach, "Cutting edge: control of $\mathrm{CD}^{+} \mathrm{T}$ cell activation by $\mathrm{CD} 4^{+} \mathrm{CD} 25^{+}$immunoregulatory cells," Journal of Immunology, vol. 167, no. 3, pp. 1137-1140, 2001.

[82] L. Chaperot, O. Manches, J. Q. Mi et al., "Differentiation of anti-tumour cytotoxic $\mathrm{T}$ lymphocytes from autologous peripheral blood lymphocytes in non-Hodgkin's lymphomas," British Journal of Haematology, vol. 119, no. 2, pp. 425-431, 2002.

[83] H. W. Lim, P. Hillsamer, A. H. Banham, and C. H. Kim, "Cutting edge: direct suppression of B cells by $\mathrm{CD} 4{ }^{+} \mathrm{CD} 25^{+}$ regulatory T cells," Journal of Immunology, vol. 175, no. 7, pp. 4180-4183, 2005.

[84] T. J. Curiel, G. Coukos, L. Zou et al., "Specific recruitment of regulatory $\mathrm{T}$ cells in ovarian carcinoma fosters immune privilege and predicts reduced survival," Nature Medicine, vol. 10, no. 9, pp. 942-949, 2004.

[85] J. Carreras, A. Lopez-Guillermo, B. C. Fox et al., "High numbers of tumor-infiltrating FOXP3-positive regulatory $\mathrm{T}$ cells are associated with improved overall survival in follicular lymphoma," Blood, vol. 108, no. 9, pp. 2957-2964, 2006.

[86] Z. Z. Yang, A. J. Novak, M. J. Stenson, T. E. Witzig, and S. M. Ansell, "Intratumoral $\mathrm{CD} 4^{+} \mathrm{CD} 25^{+}$regulatory T-cellmediated suppression of infiltrating $\mathrm{CD} 4^{+} \mathrm{T}$ cells in B-cell
non-Hodgkin lymphoma," Blood, vol. 107, no. 9, pp. 36393646, 2006.

[87] R. C. Verdonk, E. B. Haagsma, M. R. Jonker et al., "Effects of different immunosuppressive regimens on regulatory $\mathrm{T}$ cells in noninflamed colon of liver transplant recipients," Inflammatory Bowel Diseases, vol. 13, no. 6, pp. 703-709, 2007.

[88] B. G. Richendollar, R. E. Tsao, P. Elson et al., "Predictors of outcome in post-transplant lymphoproliferative disorder: an evaluation of tumor infiltrating lymphocytes in the context of clinical factors," Leukemia and Lymphoma, vol. 50, no. 12, pp. 2005-2012, 2009. 


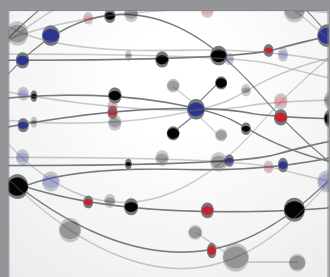

The Scientific World Journal
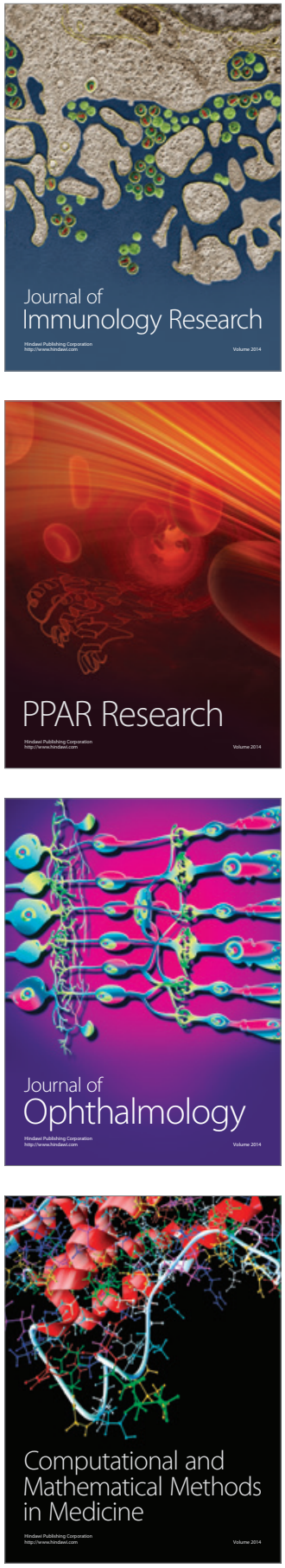

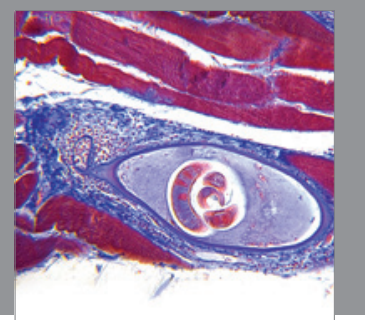

Gastroenterology

Research and Practice
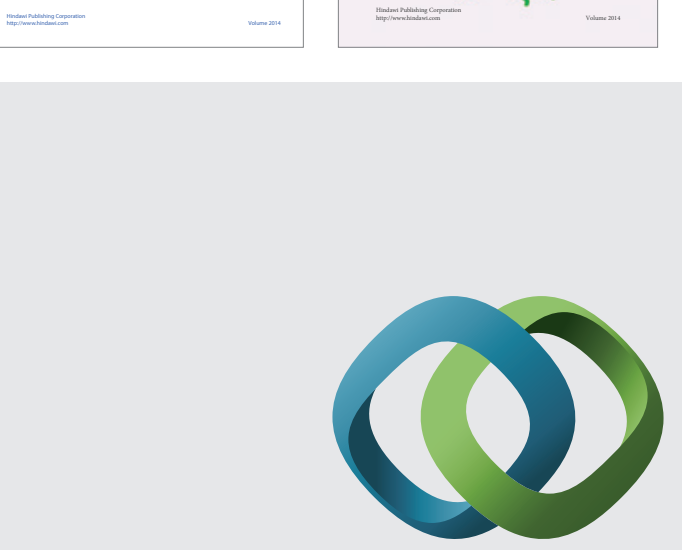

\section{Hindawi}

Submit your manuscripts at

http://www.hindawi.com
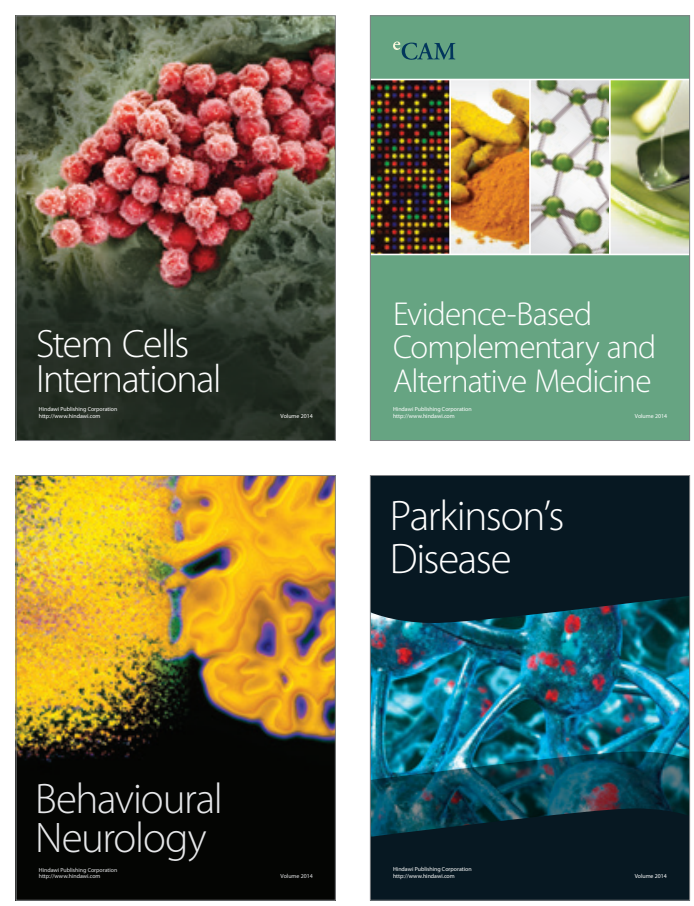

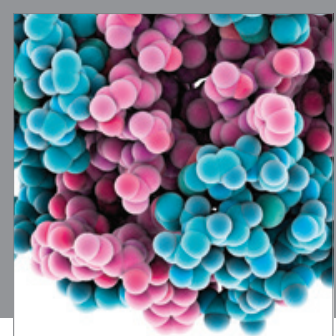

Journal of
Diabetes Research

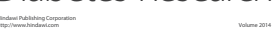

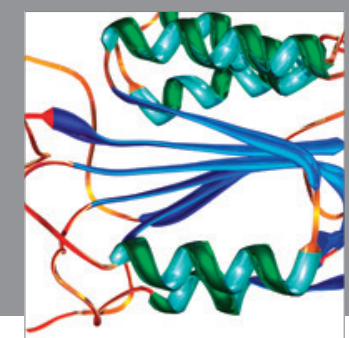

Disease Markers
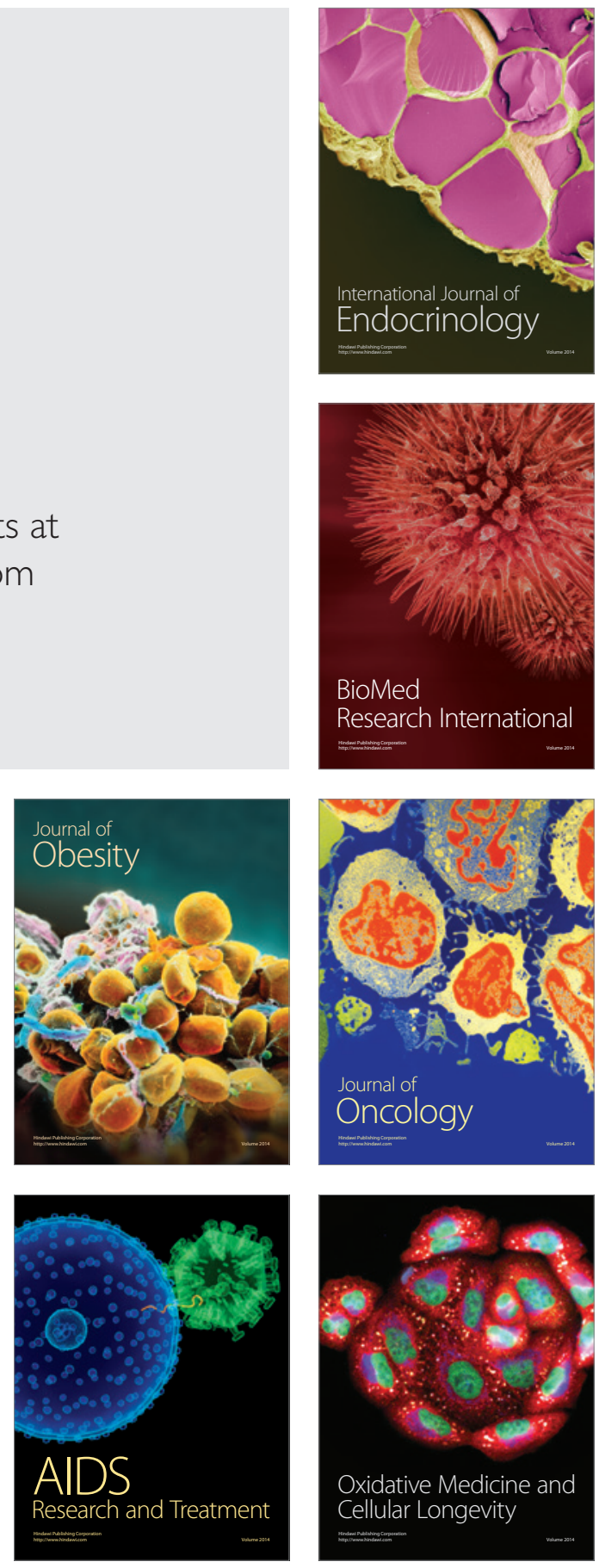